\title{
Recommendations on screening for colorectal cancer in primary care
}

\author{
Canadian Task Force on Preventive Health Care*
}

CMAJ Podcasts: author interview at https://soundcloud.com/cmajpodcasts/151125-guide

Competing interests: None declared.

This article has been peer reviewed.

*The authors of this article are listed at the end of the article, under "guideline writing group."

The complete list of current members of the Canadian Task Force on Preventive Health Care is available at www.canadiantaskforce.ca/ members_eng.html.

Correspondence to: Canadian Task Force on Preventive Health Care, info@ canadiantaskforce.ca

CMAJ 2016. DOI: 10.1503 /cmaj.151125

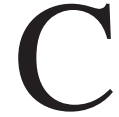
olorectal cancer is the second most common cause of cancer-related death in men and the third most common in women $;^{1}$ the lifetime probabilities of dying from colorectal cancer among men and women are $3.5 \%$ and $3.1 \%$, respectively. ${ }^{2}$ Although the burden of colorectal cancer varies across Canada, ${ }^{3}$ it is estimated that 25000 Canadians received a diagnosis of colorectal cancer in 2015 (incidence 49 per 100000 population) and that 9300 will die from the disease (mortality 17 per 100000 ). ${ }^{1}$ The incidence and mortality of colorectal cancer are low until middle age and rise rapidly thereafter (Figure 1). ${ }^{1,4}$

Most colorectal cancers appear to arise from colonic polyps that develop slowly and sometimes transform to cancers. ${ }^{5}$ This is the rationale for screening programs that aim to reduce deaths due to colorectal cancer by detecting and removing polyps and/or early-stage colorectal cancers. Implementation of organized screening programs in some Canadian provinces has been associated with an increase in the number of individuals screened, ${ }^{6}$ and other provinces are in the process of implementing such programs (Appendix 1, available at www.cmaj.ca/lookup/ suppl/doi:10.1503/cmaj.151125/-/DC1). Cur- rently, all Canadian programs recommend screening with guaiac fecal occult blood testing (gFOBT) or fecal immunochemical testing (FIT).

This guideline presents recommendations for screening for colorectal cancer in asymptomatic adults aged 50 years and older who are not at high risk for colorectal cancer, and it updates previous Canadian Task Force on Preventive Health Care recommendations from 2001. ${ }^{7}$ The 2001 guideline recommended annual or biennial FOBT (grade A recommendation) and flexible sigmoidoscopy every five years (grade B recommendation) in asymptomatic people older than 50 years. The guideline did not recommend whether these screening modalities should be used alone or in combination (grade C), ${ }^{7,8}$ or whether to include or exclude colonoscopy as an initial screening test for colorectal cancer. Given the major changes in technology and practice since 2001, the guideline has been updated based on the most recent data available to provide guidance for primary care practitioners on different screening tests, screening intervals and recommended ages to start and stop screening.

\section{Methods}

The Canadian Task Force on Preventive Health Care is an independent panel of clinicians and methodologists that makes recommendations about clinical manoeuvres aimed at primary and secondary prevention (www.canadiantaskforce. ca). The recommendations were developed by a task force work group, in collaboration with the Public Health Agency of Canada and the National Colorectal Cancer Screening Network. A representative of the network was a member of the task force work group, and the guideline protocol, systematic review and draft guideline all underwent external review by experts and other stakeholders. The task force used the Grading of Recommendations Assessment, Development and Evaluation (GRADE) system to determine the quality of evidence and strength of recommendations (Box 1). ${ }^{9}$ Patients' preferences 
were sought in developing the systematic review (see "Values and preferences" section) and in formulating the knowledge translation tools that accompany this guideline.

The work group established the research questions and analytical framework (Appendix 3, available at www.cmaj.ca/lookup/suppl/doi: 10.1503/cmaj.151125/-/DC1) for the guideline. Key and contextual questions (http://canadian taskforce.ca/perch/resources/colorectal-protocol -v2-3final1.pdf) examined the benefits and harms of screening for colorectal cancer with any available screening test. The task force focused on clinically important outcomes, which included all-cause mortality, colorectal cancer mortality and incidence of late-stage (stage III or IV, or Dukes C or D) colorectal cancer. Because sufficient evidence was available on these clinically important outcomes, polyps (an intermediate outcome) were not considered in the development of this guideline, especially given that only a limited proportion of polyps appear to develop into colorectal cancer. ${ }^{5}$

The systematic review is based on the final peer-reviewed protocol and was conducted by the Evidence Review and Synthesis Centre at McMaster University (Hamilton, Ontario), which searched MEDLINE, the Cochrane Library and Embase for screening evidence from Jan. 1, 2000, to Nov. 21, 2013, with a second search to June 29, 2015. An update search was conducted to Dec. 8, 2015. The complete systematic review can be obtained from the task force at www. canadiantaskforce.ca.

The task force uses a rigorous and collaborative usability testing process to develop knowledge translation tools targeting various end-user groups (e.g., clinicians and patients) to accompany its guidelines. All tools are informed by feedback from clinicians (for clinician and patient tools) and patients (for patient tools) obtained through interviews, focus groups and/or surveys.

Information about the task force's methods is available from the task force website (http:// canadiantaskforce.ca/methods/methods-manual) and elsewhere. ${ }^{10}$

\section{Recommendations}

\section{Screening in adults aged $\mathbf{5 0}$ to $\mathbf{7 4}$}

We recommend screening adults aged 60 to 74 years for colorectal cancer with FOBT ( $g F O B T$ or FIT) every two years or flexible sigmoidoscopy every 10 years. (Strong recommendation; moderate-quality evidence)

We recommend screening adults aged 50 to 59 years for colorectal cancer with FOBT ( $g F O B T$ or FIT) every two years or flexible sig- moidoscopy every 10 years. (Weak recommendation; moderate-quality evidence)

A summary of the recommendations is shown in Box 2. The systematic review ${ }^{11}$ identified four eligible randomized controlled trials (RCTs) using gFOBT, ${ }^{12-15}$ one using FIT $^{16}$ and four using flexible sigmoidoscopy..$^{17-20}$

A meta-analysis of multiple studies involving people aged 45-80 years showed that gFOBT reduced mortality from colorectal cancer (risk ratio $[\mathrm{RR}] 0.82,95 \%$ confidence interval $[\mathrm{CI}]$ 0.73-0.92) and incidence of late-stage colorectal cancer (RR 0.92, 95\% CI 0.85-0.99). ${ }^{11}$ The absolute reduction in death from colorectal cancer was 2.7 per 1000 screened, so the number needed to screen to prevent one death was 377 (95\% CI 249-887) over a median follow-up period of 18.25 (9-30) years. Pooled analyses showed that flexible sigmoidoscopy reduced colorectal cancer mortality (RR $0.74,95 \%$ CI $0.67-0.82$ ) and incidence of late-stage colorectal cancer (RR 0.73, 95\% CI 0.66-0.82) among people aged 55-74 years. ${ }^{11}$ For flexible sigmoidoscopy, the absolute reduction in death from colorectal cancer was 1.2 per 1000 screened, and the number needed to screen was 850 (95\% CI 673-12052) over a shorter median follow-up period of 11.3 (7.0-11.9) years. No change was reported in allcause mortality with gFOBT (RR $1.00,95 \%$ CI 1.00-1.01) or flexible sigmoidoscopy (RR 1.00, 95\% CI 0.96-1.00). ${ }^{11}$

Two of the RCTs on gFOBT reported results by age. ${ }^{14,15}$ One of these found a significant reduction in mortality from colorectal cancer among patients

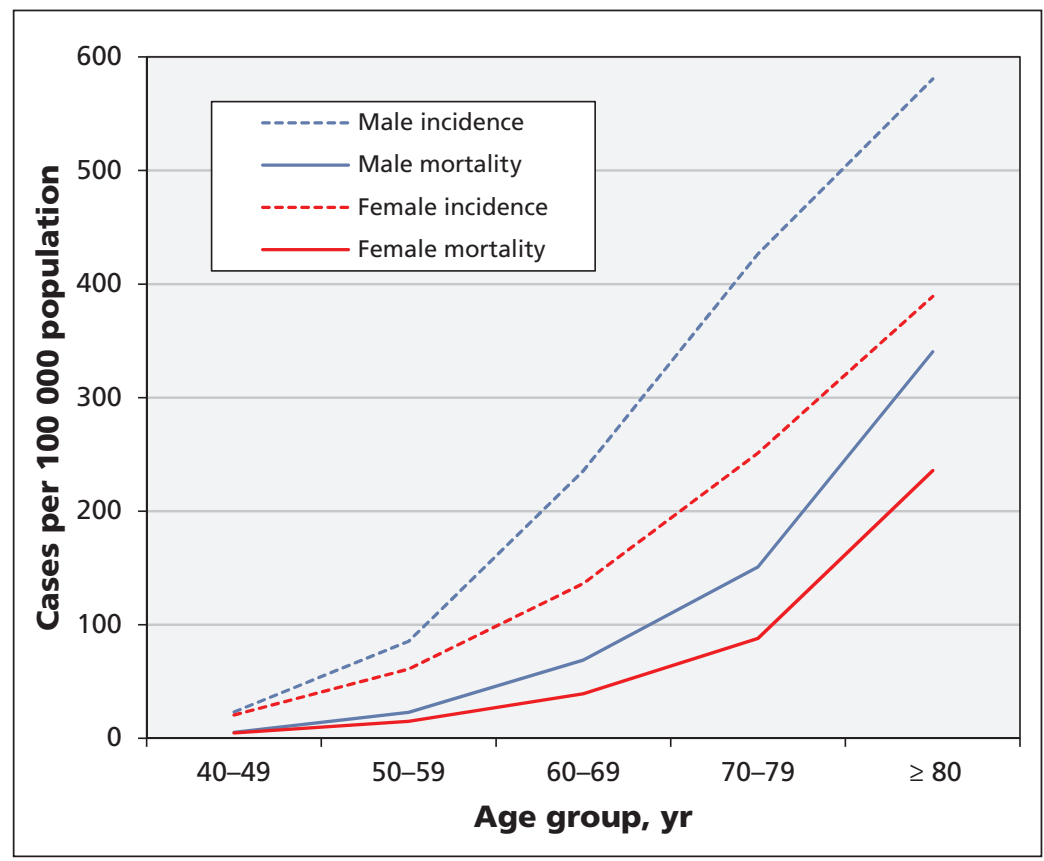

Figure 1: Estimated incidence and mortality from colorectal cancer in Canada in 2015, by sex. Estimates are based on 2011 census data. ${ }^{1,4}$ 
aged 60-69 years (Table 1) but no reduction among patients under 60 years. ${ }^{14}$ The other found a significant benefit of screening in patients aged 60-69 years and in patients older than 70 years. ${ }^{15}$ One RCT on flexible sigmoidoscopy reported results by age..$^{19}$ It found a reduction in colorectal

\section{Box 1: Grading of recommendations}

Recommendations are graded according to the Grading of Recommendations Assessment, Development and Evaluation (GRADE) system. ${ }^{9}$ GRADE offers two strengths of recommendation: strong and weak. The strength of recommendations is based on the quality of supporting evidence, the degree of uncertainty about the balance between desirable and undesirable effects, the degree of uncertainty or variability in values and preferences, and the degree of uncertainty about whether the intervention represents a wise use of resources.

Strong recommendations are those for which the Canadian Task Force on Preventive Health Care is confident that the desirable effects of an intervention outweigh its undesirable effects (strong recommendation for an intervention) or that the undesirable effects of an intervention outweigh its desirable effects (strong recommendation against an intervention). A strong recommendation implies that most individuals will be best served by the recommended course of action.

Weak recommendations are those for which the desirable effects probably outweigh the undesirable effects (weak recommendation for an intervention) or undesirable effects probably outweigh the desirable effects (weak recommendation against an intervention) but appreciable uncertainty exists. Weak recommendations result when the balance between desirable and undesirable effects is small, the quality of evidence is lower, or there is more variability in the values and preferences of patients. A weak recommendation implies that most people would want the recommended course of action but that many would not. Clinicians must recognize that different choices will be appropriate for each individual, so they must help each person arrive at a management decision consistent with his or her values and preferences. Policy-making will require substantial debate and involvement of various stakeholders.

Evidence is graded as high, moderate, low or very low, based on how likely further research is to change our confidence in the estimate of effect (Appendix 2, available at www.cmaj.ca/lookup/suppl/doi:10.1503/cmaj.151125/-/DC1).

Box 2: Summary of recommendations for clinicians and policy-makers

We recommend screening adults aged 60 to 74 years for colorectal cancer with FOBT (either gFOBT or FIT) every two years or flexible sigmoidoscopy every 10 years. (Strong recommendation; moderate-quality evidence)

We recommend screening adults aged 50 to 59 years for colorectal cancer with FOBT (either gFOBT or FIT) every two years or flexible sigmoidoscopy every 10 years. (Weak recommendation; moderate-quality evidence)

We recommend not screening adults aged 75 years and older for colorectal cancer. (Weak recommendation; low-quality evidence)

We recommend not using colonoscopy as a screening test for colorectal cancer. (Weak recommendation; low-quality evidence)

These recommendations apply to adults aged 50 years and older who are not at high risk for colorectal cancer. They do not apply to those with previous colorectal cancer or polyps, inflammatory bowel disease, signs or symptoms of colorectal cancer, history of colorectal cancer in one or more first-degree relatives, or adults with hereditary syndromes predisposing to colorectal cancer (e.g., familial adenomatous polyposis, Lynch syndrome).

Note: $\mathrm{FIT}$ = fecal immunochemical testing, gFOBT = guaiac fecal occult blood testing. cancer mortality with screening only among those aged $65-74$ years (RR $0.65,95 \%$ CI $0.52-0.82) .{ }^{19}$ It did not find a significant benefit of screening in the 55-64-year age group (RR 0.84, 95\% CI 0.671.06). ${ }^{19}$ However, both the gFOBT and flexible sigmoidoscopy RCTs were underpowered to detect an effect among those under 60 or over 70 years. ${ }^{11}$ There was no convincing evidence that the relative benefits of gFOBT and flexible sigmoidoscopy are lower among people aged 50-59 years, compared with older patients. However, assuming that the relative benefit is similar at all ages, the absolute benefit of screening must be lower among younger (50-59 yr) people than among those aged 60-74 years, owing to the rise in incidence with age; consequently, large numbers are needed to detect an effect in those under 60 years (Figure 1, Table 1).

In the judgment of the task force, gFOBT and flexible sigmoidoscopy are both reasonable screening tests for patients aged 50-74 years. This recommendation places a relatively higher value on the potential for additional years of life saved in younger patients and a relatively lower value on the lack of significance for mortality benefit in subgroup analyses of younger participants. However, in the judgment of the task force, the lower absolute benefit expected from screening in people aged 50-59 years warrants a weak recommendation, as compared with the strong recommendation for people aged 60-74 years. Making separate recommendations for the two age groups places a relatively higher value on the different balance of benefits to harms by age, and a relatively lower value on the added complexity of having recommendations based on age groups.

The only identified RCT of screening with FIT did not find a significant reduction in colorectal cancer mortality. ${ }^{16}$ This study was conducted in China with a single round of screening but had short follow-up (median $8 \mathrm{yr}$ ) and a young population (60\% aged 30-49 yr), so any effect would be difficult to detect. In the absence of robust RCT data, we referred to a recent systematic review conducted by Cancer Care Ontario's FIT Guidelines Expert Panel, ${ }^{22}$ which we assessed using AMSTAR (A Measurement Tool to Assess Systematic Reviews, http:// amstar.ca), the results of which can be found in Appendix 4, available at www.cmaj.ca/lookup/ suppl/doi:10.1503/cmaj.151125/-/DC1. The systematic review compared FIT with gFOBT for population-based colorectal cancer screening. The review included two random comparisons, in which patients were assigned to either FIT or gFOBT, ${ }^{23,24}$ and two other studies, in which all patients were assessed using both FIT and gFOBT. ${ }^{25,26}$ 
Based on the Cancer Care Ontario systematic review, ${ }^{22}$ FIT appears to provide greater sensitivity and higher rates of detection for colorectal cancer and advanced adenoma than gFOBT, with an additional benefit of increased participation rates with FIT over gFOBT. Specificity was generally similar for the two tests. The authors of the review did note that, when using the manufacturer's standard cut-off levels, the positive predictive value for detecting colorectal cancer and advanced adenomas does not differ between FIT and standard gFOBT, and, in general, the positivity rates for FIT vary according to the cut-off used. ${ }^{22}$ They recommend that program planners consider these factors in implementation of organized screening programs.

Similarly, the 2008 systematic review on colorectal cancer screening from the US Preventive Services Task Force ${ }^{27}$ concluded that FIT could be substituted for gFOBT for screening for colorectal cancer despite some limitations. In its most recent October 2015 draft review, ${ }^{28}$ the US task force stated, "given at least equal and likely better CRC [colorectal cancer] detection and patient adherence, FITs are preferable to gFOBT." 28

The Canadian task force's recommended screening interval of two years for FOBT is based on the interval used in most of the gFOBT RCTs. One study compared gFOBT screening every year or every two years with no screening. ${ }^{15}$ Among people aged 60-69, both one-year and two-year screening intervals reduced colorectal cancer mortality. Although only the annual interval was beneficial in the population aged 70 and older (annual interval, RR 0.47, 95\% CI 0.26-0.84; biennial interval, RR 0.66, 95\% CI $0.35-1.26$ ), there was no statistical evidence that biennial screening was less effective (the 95\% CIs overlapped substantially for the two age groups, and no global test of interaction by age was reported). Although there is no evidence that adherence improves with biennial versus annual screening, the task force recommends the less burdensome two-year screening interval for FOBT; additional studies are required to determine whether annual FOBT testing would lead to incremental clinical benefit.

For flexible sigmoidoscopy, three of the four $\operatorname{RCTs}^{17,18,20}$ evaluated the effect of a one-time screen over a median follow-up period of 11 years but did not compare different screening intervals or evaluate the effect of repeated screening versus once-per-lifetime screening. The other $\mathrm{RCT}^{19}$ evaluated a strategy of flexible sigmoidoscopy at baseline and then again after three to five years of follow-up; the magnitude of the mortality benefit at a median of 11.9 years of follow-up was similar to that seen in the other three trials. The task force's recommendation of a 10-year screening interval is based on the following: follow-up data that show a reduction in both colorectal cancer mortality and incidence with screening with flexible sigmoidoscopy at least until 11 years of follow-up; Kaplan-Meier survival curves from the published RCTs, which show that the beneficial effects of screening with flexible sigmoidoscopy are maintained over the full duration of follow-up; and observational data $^{21,29,30}$ suggesting that the mortality benefits of screening with flexible sigmoidoscopy last for at least 10-15 years. ${ }^{11}$ Additionally, as outlined in Table 1, the numbers needed to screen for colorectal cancer mortality by age group appear lower for flexible sigmoidoscopy. Consequently, the task force recommends a screening interval of 10 years by examiners who are trained in this technique. Patients without evidence of colorectal cancer or its precursor polyps following flexible sigmoidoscopy should not be screened again (by any method) for 10 years.

Although our recommendations might lead to increased use of flexible sigmoidoscopy, the training of providers, preparation required and resources needed for flexible sigmoidoscopy are less than for colonoscopy. Also, FOBT remains an acceptable alternative if flexible sigmoidoscopy is not available.

False-positive and false-negative results were the only direct harms reported for gFOBT and FIT in the included studies. ${ }^{11}$ The false-positive rate was $1.22 \%$ and the false-negative rate was $0.55 \%$ for gFOBT (uncontrolled studies for all harms; very low-quality evidence). The rate of false-positive results for FIT ranged from $5.55 \%$ to $12.89 \%$, depending on the threshold used for

Table 1: Number needed to screen for colorectal cancer mortality by age groups with varying underlying baseline risk ${ }^{11}$

\begin{tabular}{|lccc|}
\hline Screening test & Age group, yr & $\begin{array}{c}\text { Absolute risk } \\
\text { reduction, \%* }\end{array}$ & NNS (95\% Cl) \\
\hline Biennial gFOBT & $<60(45-59)$ & 0.0377 & $2655(1757-6244)$ \\
\hline Biennial gFOBT & $\geq 60(60-80)$ & 0.2032 & $492 \quad(326-1157)$ \\
$\begin{array}{l}\text { Flexible } \\
\text { sigmoidoscopy }\end{array}$ & $<60(45-59)$ & 0.0540 & $1853(1441-2713)$ \\
$\begin{array}{l}\text { Flexible } \\
\text { sigmoidoscopy }\end{array}$ & $\geq 60(60-80)$ & 0.2912 & $343 \quad(267-503)$ \\
\hline
\end{tabular}

Note: $\mathrm{Cl}=$ confidence interval, gFOBT = guaiac fecal occult blood testing, NNS = number needed to screen, $\mathrm{RR}=$ relative risk.

*The estimates of absolute risk reduction in colorectal cancer mortality for screening versus control and NNS to prevent one death from colorectal cancer are based on age-specific baseline risk of dying from colorectal cancer (obtained from SEER Cancer Statistics Review $1975-2012,{ }^{21}$ the RR reduction (obtained from pooled estimate for colorectal cancer mortality for biennial gFOBT [RR reduction $0.8215 ; 95 \% \mathrm{Cl} 0.7303-0.9241$ ] and flexible sigmoidoscopy screening [RR reduction $0.7442 ; 95 \% \mathrm{Cl} 0.6710-0.8253]$ ) and the life expectancy over which the patient is expected to be screened. ${ }^{11}$ 
screening (100 ng/mL to $50 \mathrm{ng} / \mathrm{mL})$. The rate of false-negative results ranged from $0.02 \%$ to $0.13 \%$, depending on threshold values. The review ${ }^{11}$ did not identify any data on the levels of overdiagnosis associated with screening.

Detailed information on the different types of gFOBT and FIT, their test characteristics and cut-off points used by Canadian provinces can be found in Appendix 1. Provinces that elect to use gFOBT for screening may wish to consider using only high-sensitivity gFOBT. For FIT specifically, each individual laboratory should set its cut-off point based on the guidance from its provincial screening program.

Harms following flexible sigmoidoscopy were rare (intestinal perforation occurred in $0.001 \%$ of patients, minor bleeding in $0.05 \%$, major bleeding in $0.009 \%$ and death in $0.015 \%) .{ }^{11}$

Harms of diagnostic colonoscopy (as a followup test for either positive FOBT or flexible sigmoidoscopy screening) include intestinal perforation $(0.061 \%$ of patients), minor bleeding $(0.27 \%)$, major bleeding $(0.11 \%)$ and death $(0.035 \%) .{ }^{11}$ The harms for diagnostic colonoscopy are based on all colonoscopies performed in symptomatic patients. Although important, distinguishing harms from therapeutic versus nontherapeutic colonoscopies was beyond the scope of the Evidence Review and Synthesis Centre's systematic review and would not have influenced our recommendations.

\section{Screening in adults aged $\mathbf{7 5}$ and older}

We recommend not screening adults aged 75 years and older for colorectal cancer. (Weak recommendation; low-quality evidence)

The recommended age to stop screening is 75 years, based on reduced life expectancy in older groups as well as the included age groups in the RCTs identified in the systematic review ${ }^{11}$ (varied, but upper age groups included were 64, 74, 75 and $80 \mathrm{yr}$ for gFOBT; and 64 and $74 \mathrm{yr}$ for flexible sigmoidoscopy). Although no RCTs have shown improvement in colorectal cancer mortality or morbidity among adults over the age of 74 , existing trials are underpowered to detect a clinically important difference in this population. However, given that incidence rises with age (Table 1), and that this recommendation is based on low-quality evidence, adults over 74 years of age who do not have illnesses that affect their quality of life and/or their lifespan may be less concerned with the lack of trials showing benefit or the potential harm. They should discuss screening with their primary care provider to determine their most appropriate screening option based on their personal values and preferences.

\section{Screening using colonoscopy}

We recommend not using colonoscopy as a primary screening test for colorectal cancer. (Weak recommendation; low-quality evidence)

Although colonoscopy may offer clinical benefits that are similar to or greater than those associated with flexible sigmoidoscopy, direct evidence of its efficacy in comparison with the other screening tests (in particular FIT) is lacking. ${ }^{11}$ Wait lists for colonoscopy are long in Canada and have increased over the years. ${ }^{31}$ Because of higher human resource requirements (requires a specialist such as a gastroenterologist) and greater potential for harms, the ongoing RCTs would have to show greater efficacy of colonoscopy (in comparison with other tests) before its routine use for screening could be recommended.

Only very low-quality evidence was available to assess the harms of screening colonoscopy. The harms include intestinal perforation ( $0.05 \%$ of patients), minor bleeding $(0.08 \%)$, major bleeding requiring hospital admission $(0.1 \%)$ and death $(0.002 \%) .{ }^{11}$

This recommendation is weak, given the level of uncertainty over the effectiveness and harms of colonoscopy as a screening test. It reflects a relatively higher value placed on the lack of direct evidence from RCTs of incremental benefit for colonoscopy and on the opportunity costs of using colonoscopy for population screening. The recommendation places a relatively lower value on the indirect evidence suggesting that the clinical benefits of colonoscopy could outweigh its clinical harms. It also places a lower value on economic modelling. There are currently four trials underway investigating the mortality benefit of screening colonoscopy. These will be considered as the results become available.

Despite this recommendation, some patients may choose to undergo screening with colonoscopy. Based on the data from patients screened with flexible sigmoidoscopy and observational studies of colonoscopy, patients without evidence of colorectal cancer or its precursor polyps on colonoscopy should not be screened again (by any method) for 10 years.

When patients specifically request colonoscopy as a screening test, clinicians should discuss the evidence regarding FOBT or flexible sigmoidoscopy (where available) and help patients to make a decision that is consistent with their personal values and preferences, local availability and expected wait times.

\section{Other screening tests}

No RCT evidence was identified on the mortality benefits of screening with computed tomographic colonography, barium enema, digital 
rectal examination, serologic tests, fecal DNA testing or other tests, and therefore no recommendations are made for these screening tests. A recent study ${ }^{32}$ on multitarget stool DNA testing (including quantitative molecular assays for KRAS mutations, aberrant NDRG4 and BMP3 methylation, and $\beta$-actin, plus a hemoglobin immunoassay) suggests that this test is more sensitive than FIT but has an even higher falsepositive rate, potentially leading to more harm from subsequent unnecessary tests. ${ }^{11}$

\section{Considerations for implementation}

The weak recommendation for screening people aged 50-59 years versus the strong recommendation for screening people aged 60-74 is based on the less favourable balance of benefits to harms for the former, and implies that the decision to be screened will require more discussion among people aged 50-59 years. The task force has produced decision aids to assist practitioners with such discussions (available at www.canadiantaskforce.ca/ ctfphc-guidelines/2015-colorectal-cancer/clinician -recommendation-table). Screening will be more appropriate for patients aged 50-59 who are interested in a small absolute reduction in the risk of death from colorectal cancer and who are less concerned about the potential harms and inconvenience of testing. In contrast, patients aged 50-59 who are more concerned about harms and inconvenience could make a valid decision to defer screening until age 60 or older.

Fecal immunochemical testing is more sensitive and specific than both gFOBT and highsensitivity gFOBT, and is the primary screening test in all provinces with the exception of Ontario and Manitoba. ${ }^{33}$ Alberta is the most recent jurisdiction to discontinue the use of gFOBT (as of January 2014) and is now using FIT exclusively. ${ }^{34}$ Given FIT's increased sensitivity, screening programs could be designed to have a high cut-off to reduce the false-positive rate but still provide appropriate screening.

Limited access to flexible sigmoidoscopy may result in most Canadians being screened appropriately using FIT or gFOBT. However, patients who wish to be screened but prefer less frequent testing (every $10 \mathrm{yr}$ ), or are averse to stool testing with FOBT, may be more likely to choose flexible sigmoidoscopy rather than FOBT. Although flexible sigmoidoscopy is not frequently performed for screening in many jurisdictions, it may warrant further consideration because it can be completed in the same facilities as colonoscopy and using similar equipment, but without the requirement of a specialist, such as a gastroenterologist. As an exam- ple, primary care providers can refer patients for flexible sigmoidoscopy through Ontario's Registered Nurse Flexible Sigmoidoscopy program. ${ }^{35}$ The UK government is also implementing a similar program at special screening centres in England aimed at adults aged 55 and older. ${ }^{36}$ In the event that any polyps are found, they are usually removed immediately. ${ }^{37}$

As noted, harms following flexible sigmoidoscopy are rare. However, although flexible sigmoidoscopy is less resource-intensive than colonoscopy, program planners would still need to consider the implications of establishing screening facilities, training of providers, the bowel preparation required by patients and the resources needed for flexible sigmoidoscopy as compared with FOBT.

\section{Values and preferences}

Three reviews and 20 primary studies about values and preferences related to colorectal cancer screening were identified in the systematic review. ${ }^{11}$ A Canadian survey about patients' preferences ${ }^{38}$ indicated that invasiveness, level of preparation required and pain from the test were concerns. A US study ${ }^{39}$ revealed that patients' highest priorities for screening were preventing cancer (55\%), avoiding test adverse effects $(17 \%)$, minimizing false-positive results (15\%), and the combination of screening frequency, test preparation and test procedures (14\%). When patients are choosing between different screening tests, sedation needs, perceived test accuracy, confidence in completing the test, bowel preparation and frequency of tests are factors that may influence their decision.

\section{Suggested performance measures}

Suggested performance measures include the proportion of people aged 50-59 years with whom colorectal cancer screening is discussed; the proportion of people aged 60-74 undergoing FOBT or flexible sigmoidoscopy at recommended intervals; interval cancers diagnosed after a negative screening test; harms of followup testing; and colorectal cancer incidence and mortality. We also suggest measuring use of screening colonoscopy and screening with gFOBT or flexible sigmoidoscopy in people aged 75 years and older.

\section{Economic implications}

The task force examined the cost-effectiveness of screening for colorectal cancer as a contextual question. ${ }^{11}$ The systematic review ${ }^{11}$ found two Canadian modelling studies, ${ }^{40,41}$ and the Canadian Partnership Against Cancer used the Cancer Risk 
Management Model (version 2.2) ${ }^{42}$ to run specific colorectal cancer screening scenarios on behalf of the task force as an ancillary analysis. Detailed information on the findings of the Canadian Partnership Against Cancer model can be found in Appendix 5, available at www. cmaj.ca/lookup/suppl/doi:10.1503/cmaj.151125/-/ DC1. The first economic evaluation ${ }^{40}$ concluded that both incidence and mortality from colorectal cancer were greatly reduced with the use of three screening strategies compared with no screening: low-sensitivity gFOBT and FIT performed annually as well as colonoscopy performed every 10 years. It also concluded that all screening strategies are cost-effective but that low-sensitivity FIT performed annually or colonoscopy performed every 10 years offered the best value in Canada.

The second economic evaluation ${ }^{41}$ concluded that screening with annual FIT with midtest performance characteristics (sensitivity 0.81 , specificity 0.96 ) reduces the number of cancers in the lifetimes of 100000 average-risk patients by $71 \%$ and the number of deaths from colorectal cancer by $74 \%$ while saving Can $\$ 68$ per person, compared with no screening. Of note, the median accuracy for screening tests for colorectal cancer identified in the systematic review ${ }^{11}$ supporting this guideline (sensitivity 0.81 , specificity 0.95 ) is in line with the midtest performance characteristics identified in this economic evaluation.

\section{Other guidelines}

The recommendations of the current guideline are consistent with those of the previous task force guideline, which recommended screening with either FOBT or flexible sigmoidoscopy. ${ }^{7}$ Provincial screening programs recommend screening with FOBT (most recommend FIT) at least every two years (Appendix 1), which is consistent with the current task force recommendation. No province currently recommends screening with flexible sigmoidoscopy. The US Preventive Services Task Force published recommendations in $2008^{43}$ and recommended screening adults aged 50-75 with FOBT, flexible sigmoidoscopy or colonoscopy. An update of their 2008 guideline is currently underway ${ }^{28,44}$ (Table 2 ).

\section{Gaps in knowledge}

Trials investigating the mortality benefit of screening colonoscopy are underway (estimated completion dates indicated): The Northern-European Initiative on Colorectal Cancer (2026); Screening of Swedish Colons (SCREESCO) (2034); Barcelona (2021); and Colonoscopy Versus Fecal Immunochemical Test in Reducing Mortality From Colorectal Cancer (CONFIRM) (2027) (www. clinicaltrials.gov). Trials showing a mortality benefit of colonoscopy, fecal DNA assays and other tests are needed before they can be recommended for population-based screening. In addition, research about how to increase access to flexible sigmoidoscopy and colonoscopy in Canada would be useful to inform population-based screening with these tests. More data are needed on the effectiveness of FIT in all age groups, on all screening tests in populations under 60 or over 74 years of age and on the impact of screening on overdiagnosis and overtreatment. Monitoring for these harmful outcomes at a national level is recommended to address this research gap.

\begin{tabular}{|c|c|c|c|c|c|c|}
\hline \multirow{4}{*}{$\begin{array}{l}\text { Guideline } \\
\text { Age group and } \\
\text { recommendation }\end{array}$} & \multicolumn{2}{|c|}{$\begin{array}{l}\text { Canadian Task Force on } \\
\text { Preventive Health Care, } 2001^{7}\end{array}$} & \multicolumn{2}{|c|}{$\begin{array}{l}\text { Canadian Task Force on } \\
\text { Preventive Health, current }\end{array}$} & \multicolumn{2}{|c|}{$\begin{array}{c}\text { US Preventive Services Task Force; } \\
\text { draft, } 2015^{28}\end{array}$} \\
\hline & $>50 \mathrm{yr}$ & Screen & $50-59 \mathrm{yr}$ & Screen (weak) & $50-75 \mathrm{yr}$ & Screen (grade A) \\
\hline & & & $60-74 \mathrm{yr}$ & Screen (strong) & $76-80 \mathrm{yr}$ & $\begin{array}{l}\text { Conditional screen } \\
\text { (grade C) }\end{array}$ \\
\hline & & & $>75 \mathrm{yr}$ & $\begin{array}{l}\text { Do not screen } \\
\text { (weak) }\end{array}$ & & \\
\hline \multirow[t]{3}{*}{$\begin{array}{l}\text { Modality and } \\
\text { interval }\end{array}$} & gFOBT or FIT & $\begin{array}{l}\text { Every } 1 \text { or } 2 \mathrm{yr} \\
\text { (grade A) }\end{array}$ & gFOBT or FIT & Every 2 yr & gFOBT or FIT & Every year \\
\hline & $\begin{array}{l}\text { Flexible } \\
\text { sigmoidoscopy }\end{array}$ & Every $5 \mathrm{yr}$ & $\begin{array}{l}\text { Flexible } \\
\text { sigmoidoscopy }\end{array}$ & Every $10 \mathrm{yr}$ & $\begin{array}{l}\text { Flexible } \\
\text { Sigmoidoscopy }\end{array}$ & $\begin{array}{l}\text { Every } 10 \text { yr plus FIT } \\
\text { every year }\end{array}$ \\
\hline & Colonoscopy & $\begin{array}{l}\text { Insufficient } \\
\text { evidence to } \\
\text { include or } \\
\text { exclude } \\
\text { (grade C) }\end{array}$ & Colonoscopy & $\begin{array}{l}\text { Do not } \\
\text { recommend }\end{array}$ & Colonoscopy & Every $10 \mathrm{yr}$ \\
\hline
\end{tabular}




\section{Conclusion}

Screening for colorectal cancer with FOBT or flexible sigmoidoscopy reduces mortality from colorectal cancer, and the direct harms associated with these screening tests are minimal. We recognize that provincial screening programs do not include flexible sigmoidoscopy as one of their screening options. Administrators of these programs may wish to weigh the benefits versus cost implications of flexible sigmoidoscopy as compared with FOBT and explore alternative care providers trained in this procedure, such as nurse practitioners or family physicians, as well as screening facilities outside of hospitals.

The strong recommendation to screen people aged 60-74 years with gFOBT, FIT or flexible sigmoidoscopy indicates that primary care practitioners should offer screening to all patients in this age group. The weak recommendation to screen people aged 50-59 with gFOBT, FIT or flexible sigmoidoscopy indicates that a more nuanced discussion about harms and benefits will be required in this population. Similarly, in people aged 75 and older, primary care providers and patients should discuss individual screening preferences. Regardless of age, primary care providers should discuss the most appropriate choice of test with patients who are interested in screening, considering patient values and preferences as well as local test availability.

\section{References}

1. Canadian Cancer Society's Advisory Committee on Cancer Statistics. Canadian cancer statistics 2015. Toronto: Canadian Cancer Society; 2015. Available: www.cancer.ca/ /media/cancer. $\mathrm{ca} / \mathrm{CW} /$ cancer\%20information/cancer\%20101/Canadian\%20 cancer\%20statistics/Canadian-Cancer-Statistics-2015-EN.pdf (accessed 2015 Aug. 31)

2. Canadian Cancer Society's Advisory Committee on Cancer Statistics. Canadian cancer statistics 2014. Toronto: Canadian Cancer Society; 2014. Available: www.cancer.ca/ /media/cancer.ca/ CW/cancer\%20information/cancer\%20101/Canadian\%20cancer $\% 20$ statistics/Canadian-Cancer-Statistics-2014-EN.pdf (accessed 2015 Mar. 31).

3. Colorectal Cancer Network (CRCNet) comprehensive report. Toronto: Cancer Care Ontario; 2011.

4. Age and sex highlight tables, 2011 census. Ottawa: Statistics Canada; 2015. Available: www12.statcan.gc.ca/census-recensement /2011/dp-pd/hlt-fst/as-sa/index-eng.cfm?Lang=E (accessed 2015 Aug. 18).

5. Muto T, Bussey HJ, Morson BC. The evolution of cancer of the colon and rectum. Cancer 1975;36:2251-70.

6. The 2014 cancer system performance report. Toronto: Canadian Partnership Against Cancer; 2014. Available: www.cancerview. $\mathrm{ca} /$ idc/groups/public/documents/webcontent/sp_report_2014.pdf (accessed 2015 Mar. 31).

7. Canadian Task Force on Preventive Health Care. Colorectal cancer screening: recommendation statement from the Canadian Task Force on Preventive Health Care. CMAJ 2001;165:206-8.

8. McLeod R; Canadian Task Force on Preventive Health Care. Screening strategies for colorectal cancer: systematic review \& recommendations. Can J Gastroenterol 2001;15:647-60.

9. Schünemann H, Brozek J, Oxman A, editors. GRADE handbook for grading quality of evidence and strength of recommendation. Version 3.2 [updated March 2009]. The GRADE Working Group; 2009.

10. Connor Gorber S, Singh H, Pottie K, et al. Process for guideline development by the reconstituted Canadian Task Force on Preventive Health Care. CMAJ 2012;184:1575-81.
11. Fitzpatrick-Lewis D, Usman A, Ciliska D, et al. Screening for colorectal cancer. Ottawa: Canadian Task Force on Preventive Health Care; 2015. Available: www.canadiantaskforce.ca/ctfphc -guidelines/2015-colorectal-cancer/systematic-review (accessed 2016 Feb. 11).

12. Kronborg O, Jorgensen OD, Fenger C, et al. Randomized study of biennial screening with a faecal occult blood test: results after nine screening rounds. Scand J Gastroenterol 2004;39: 846-51.

13. Lindholm E, Brevinge $H$, Haglind E. Survival benefit in a randomized clinical trial of faecal occult blood screening for colorectal cancer. Br J Surg 2008;95:1029-36.

14. Scholefield JH, Moss SM, Mangham CM, et al. Nottingham trial of faecal occult blood testing for colorectal cancer: a 20-year follow-up. Gut 2012;61:1036-40.

15. Shaukat A, Mongin SJ, Geisser MS, et al. Long-term mortality after screening for colorectal cancer. N Engl J Med 2013;369: 1106-14.

16. Zheng S, Chen K, Liu X, et al. Cluster randomization trial of sequence mass screening for colorectal cancer. Dis Colon Rectum 2003;46:51-8.

17. Atkin WS, Edwards R, Kralj-Hans I, et al. Once-only flexible sigmoidoscopy screening in prevention of colorectal cancer: a multicentre randomised controlled trial. Lancet 2010;375: 1624-1633.

18. Hoff G, Grotmol T, Skovlund E, et al. Risk of colorectal cancer seven years after flexible sigmoidoscopy screening: randomised controlled trial. BMJ 2009;338(b1846).

19. Schoen RE, Pinsky PF, Weissfeld JL, et al. Colorectal-cancer incidence and mortality with screening flexible sigmoidoscopy. N Engl J Med 2012;366:2345-57.

20. Segnan N, Armaroli P, Bonelli L, et al. Once-only sigmoidoscopy in colorectal cancer screening: follow-up findings of the Italian Randomized Controlled Trial-SCORE. J Natl Cancer Inst 2011;103:1310-22.

21. Newcomb PA, Storer BE, Morimoto LM, et al. Long-term efficacy of sigmoidoscopy in the reduction of colorectal cancer incidence. J Natl Cancer Inst 2003;95:622-5.

22. Rabeneck L, Rumble RB, Thompson F, et al.; FIT Guidelines Expert Panel. Fecal immunochemical tests compared with guaiac fecal occult blood tests for population-based colorectal cancer screening. Can J Gastroenterol 2012;26:131-47.

23. van Rossum LG, van Rijn AF, Laheij RJ, et al. Cutoff value determines the performance of a semi-quantitative immunochemical faecal occult blood test in a colorectal cancer screening programme. Br J Cancer 2009;101:1274-81.

24. Hol L, Wilschut JA, Van Ballegooijen M, et al. Screening for colorectal cancer: random comparison of guaiac and immunochemical faecal occult blood testing at different cut-off levels. Br J Cancer 2009; 100:1103-10.

25. Allison JE, Sakoda LC, Levin TR, et al. Screening for colorectal neoplasms with new fecal occult blood tests: update on performance characteristics. J Natl Cancer Inst 2007;99:1462-70.

26. Park DI, Ryu S, Kim YH, et al. Comparison of guaiac-based and quantitative immunochemical fecal occult blood testing in a population at average risk undergoing colorectal cancer screening. Am J Gastroenterol 2010;105:2017-25.

27. Whitlock EP, Lin JS, Liles E, et al. Screening for colorectal cancer: a targeted, updated systematic review for the U.S. Preventive Services Task Force. Ann Intern Med 2008;149:638-58.

28. Lin JS, Piper MA, Perdue LA, et al. Draft evidence review. Colorectal cancer: screening. Rockville (MD): US Preventive Services Task Force; [updated 2015]. Available: www.uspreventive servicestaskforce.org/Page/Document/draft-evidence-review54/ colorectal-cancer-screening2 (accessed 2015 Dec. 14).

29. Newcomb PA, Norfleet RG, Storer BE, et al. Screening sigmoidoscopy and colorectal cancer mortality. J Natl Cancer Inst 1992;84:1572-5.

30. Selby JV, Friedman GD, Quesenberry CP Jr, et al. A case-control study of screening sigmoidoscopy and mortality from colorectal cancer. N Engl J Med 1992;326:653-7.

31. Leddin D, Armstrong D, Borgaonkar M, et al. The 2012 SAGE wait times program: survey of access to gastroenterology in Canada. Can J Gastroenterol 2013;27:83-9.

32. Imperiale TF, Ransohoff DF, Itzkowitz SH, et al. Multitarget stool DNA testing for colorectal-cancer screening. N Engl J Med 2014;370:1287-97.

33. Colorectal cancer screening guidelines across Canada: environmental scan. Toronto: Canadian Partnership Against Cancer; 2015. Available: www.cancerview.ca/cv/portal/Home/PreventionAnd Screening/PSProfessionals/PSScreeningAndEarlyDiagnosis/ ColorectalCancerScreeningPage?_afrLoop=8588379565163000\&1 ang=en\&_afrWindowMode $=0 \&$ _adf.ctrl-state $=1$ cklla0r0d_172 (accessed 2016 Feb. 10). 
34. Toward Optimized Practice (TOP) Working Group for Colorectal Cancer Screening. Colorectal cancer screening: clinical practice guideline. Edmonton: Toward Optimized Practice; [updated 2013]. Available: www.topalbertadoctors.org/download/1009/colorectal_guideline.pdf?_20150307043502 (accessed 2015 Aug. 15).

35. Registered nurse flexible sigmoidoscopy. Toronto: Cancer Care Ontario; 2015. Available: www.cancercare .on.ca/pcs/screening/coloscreening/rnfs (accessed 2015 Aug. 31).

36. Bowel cancer screening: programme overview. London (UK): Public Health England; [updated 2015]. Available: www.gov.uk/guidance/bowel-cancer-screening-programme-overview (accessed 2015 Dec. 14).

37. Bowel cancer screening. London (UK): National Health Service; [updated 2015]. Available: www.nhs. uk/conditions/bowel-cancer-screening/pages/bowel-scope-screening.aspx (accessed 2015 Dec. 14).

38. Marshall DA, Johnson FR, Phillips KA, et al. Measuring patient preferences for colorectal cancer screening using a choice-format survey. Value Health 2007;10:415-30.

39. Dolan JG, Boohaker E, Allison J, et al. Patients' preferences and priorities regarding colorectal cancer screening. Med Decis Making 2013;33:59-70 .

40. Telford JJ, Levy AR, Sambrook JC, et al. The cost-effectiveness of screening for colorectal cancer. CMAJ 2010;182:1307-13.

41. Heitman SJ, Hilsden RJ, Au F, et al. Colorectal cancer screening for average-risk North Americans: an economic evaluation. PLoS Med 2010;7:e1000370.

42. Cancer risk management model. Toronto: Canadian Partnership Against Cancer; [updated 2015]. Available: www.cancerview.ca/cancerriskmanagement (accessed 2015 June 1).

43. US Preventive Services Task Force. Screening for colorectal cancer: US Preventive Services Task Force recommendation statement. Ann Intern Med 2008;149:627-37.

44. Colorectal cancer: screening. Rockville (MD): US Preventive Services Task Force. Available: www. uspreventiveservicestaskforce.org/uspstf/uspscolo.htm (accessed 2015 May 13).

Guideline writing group: C. Maria Bacchus, Lesley Dunfield, Sarah Connor Gorber, Nathalie M. Holmes, Richard Birtwhistle, James A. Dickinson, Gabriela Lewin, Harminder Singh (nonvoting member), Scott Klarenbach (nonvoting member), Verna Mai (nonvoting member), Marcello Tonelli

Affiliations: Department of Medicine (Bacchus, Tonelli), University of Calgary, Calgary, Alta.; Public Health Agency of Canada (Dunfield [at the time of writing], Connor Gorber [at the time of writing], Holmes), Ottawa, Ont.; Canadian Agency for Drugs and Technologies in Health (Dunfield), Ottawa, Ont.; Canadian Institutes of Health Research (Connor Gorber), Ottawa, Ont.; Departments of Family Medicine and Public Health Sciences (Birtwhistle), Queen's University, Kingston, Ont.; Departments of Internal Medicine and Community Health Sciences (Singh), University of Manitoba, Winnipeg, Man.; Department of Family Medicine (Lewin), University of Ottawa, Ottawa, Ont.; Departments of Family Medicine and Community Health Sciences (Dickinson), University of Calgary, Calgary, Alta.; Department of Medicine (Klarenbach), University of Alberta, Edmonton, Alta; Canadian Partnership Against Cancer (Mai), Toronto, Ont.

Acknowledgements: The authors acknowledge the authors of the evidence review that supported this guideline (Donna Fitzpatrick-Lewis, Ali Usman, Rachel Warren, Meghan Kenny, Maureen Rice, Andy Bayer, Donna Ciliska, Diana Sherifali, Parminder Raina and Evidence Review Clinical Expert John Marshall at McMaster University); Amanda Shane and Alain Demers at the Prevention Guidelines Division and members of the Health Surveillance and Epidemiology Division at the Public Health Agency of Canada who supported the development of the guideline; and the reviewers whose comments helped us to improve this manuscript (Nancy Baxter, Heather Bryant, Jennifer Croswell, David Currow, Robert Hilsden, Elizabeth Holmes, Thomas F. Imperiale, Kami Kandola, Ed Kucharski, Bronwen McCurdy, Gilles Plourde, Dan Sadowski, Maida Sewitch, Amanda Shaw and Jill Tinmouth).

Contributors: All of the authors contributed substantially to the interpretation of the findings and to writing the article. All of the authors gave final approval of the version to be published and agreed to act as guarantors of the work.

Funding: Funding for the Canadian Task Force on Preventive Health Care is provided by the Public Health Agency of Canada and the Canadian Institutes of Health Research. The views of the funding bodies have not influenced the content of the guideline; competing interests have been recorded and addressed. The views expressed in this article are those of the authors and do not represent those of the Public Health Agency of Canada. The Cancer Risk Management Model used in developing the economic implications of screening in this guideline has been made possible through a financial contribution from Health Canada, through the Canadian Partnership Against Cancer. The assumptions and calculations underlying the simulation results were prepared by the task force, and the responsibility for the use and interpretation of these data is entirely that of the authors. The Ontario Case Costing Initiative assumes no responsibility or liability arising from any errors or from the use of any information generated from this tool and contained within this guideline. 